\title{
What if funding wasn't an issue?
}

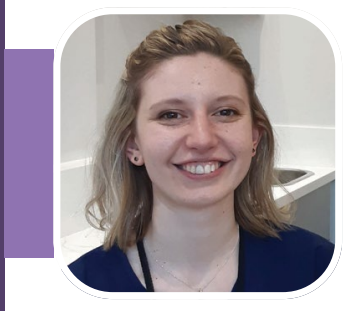

Dental hygienist and reader panellist

\section{Laura}

Marshall dreams of a nationwide network of clinics to help all patients fight dental disease.

\section{Care to daydream?}

We currently live in a time where billionaires are travelling to space! And yet in contradiction to that, we are also bombarded by the latest news educating us on much less positive realities, with headlines such as 'Warning over cuts to NHS services without $£ 10$ bn extra funding' (BBC News, September 2021). With the COVID-19 pandemic dominating our lives for the last two years,

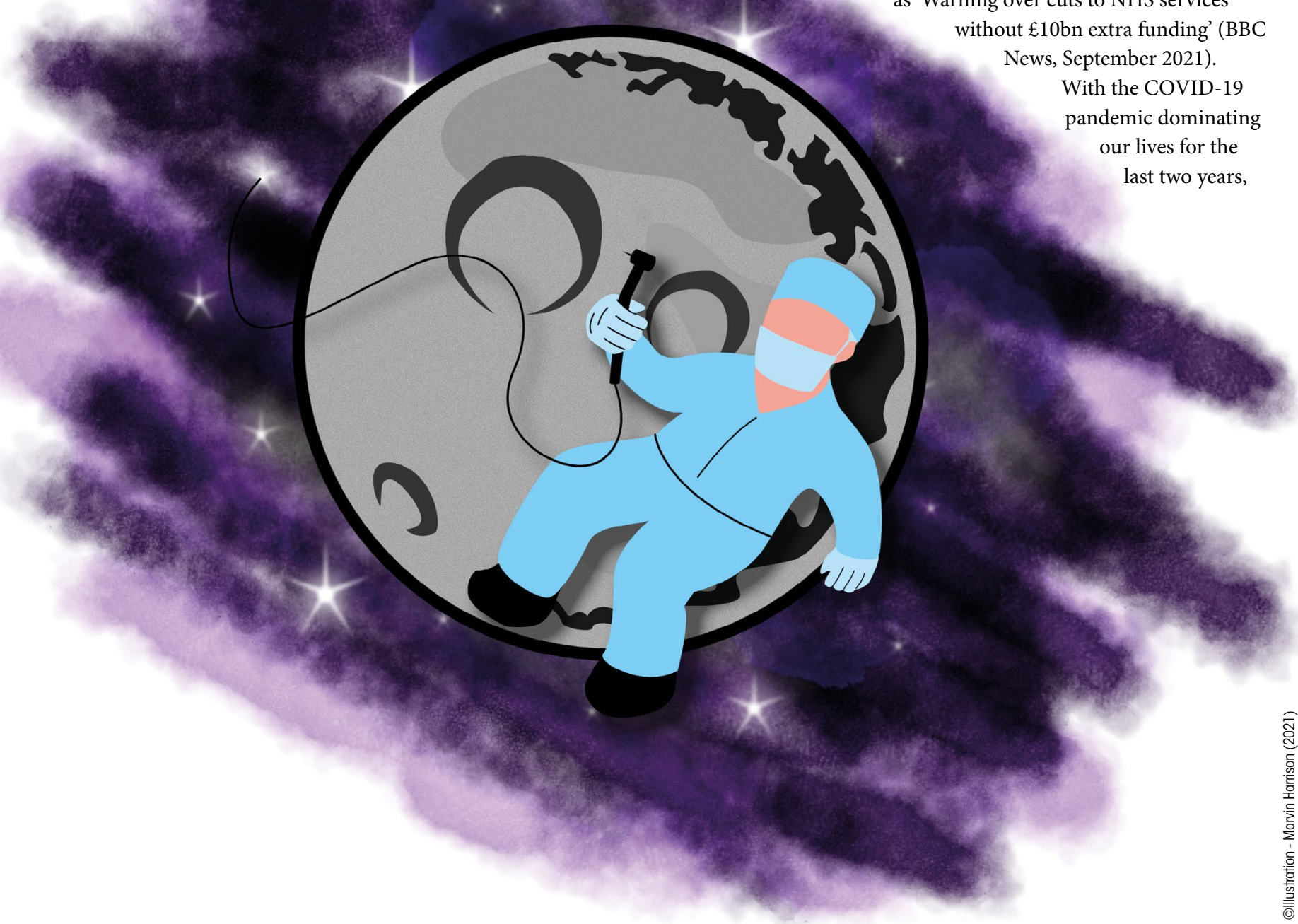


more than ever our services have fought to provide essential care whilst recognising the reality and hardships of funding. Perhaps you've noticed you've needed more equipment, more time, more rooms, more clinicians? And no doubt with the extra pressures and hours we've all put in we'd like a little more for ourselves. That's laughable, right? Well in this article I'd like you to think a little bigger than this.

The world is so often governed by finances, and those who dare to dream bigger are all too frequently deterred by the harsh reality of funding and expenditure.

In this article, although perhaps admittedly a little naive, I'd like to offer you the freedom to indulge yourself in those national lottery dreams and campaigns. Now I'm not saying we should be building dental practices on the moon, but pause for a second and stop to truly consider... What would you do if funding wasn't an issue?

Here are a few ideas from dental professionals (Box 1). advice they desperately need to help themselves, before becoming an emergency. Due to COVID these calls of desperation are all too frequent.

Being a dental hygienist in the time of the pandemic I've also played witness to the impact COVID-19 has had on periodontal care. Earlier in the year we were instructed to provide only 'urgent care': prioritising patients who are in pain. With periodontal disease often having a silent progression I worry for the patients still awaiting periodontal treatment or for those not yet diagnosed; the concern of tooth loss that could be avoidable. A lot of professionals took the time to provide individual preventative advice over the phone in replacement of face to face appointments. If funding wasn't an issue I would have preventive clinics placed all over the country so that we could refer our patients that are awaiting treatment due to the pandemic backlog or direct people who don't have the access to an NHS practice. I would enable people to help themselves in a fight against preventable dental diseases.

\section{'I would love funding to be available}

\section{to direct people to preventative clinics,}

\section{so patients are offered the preventative}

\section{advice they desperately need,}

\section{before becoming an emergency.'}

\section{For me, if funding wasn't an issue...}

I would want to create numerous prevention clinics. Dental education and prevention has always been key in the management of dental disease. Throughout the pandemic, this has only been amplified. I think about the number of calls we receive from people asking if we are taking on NHS patients. It's rare to find a practice that is. We apologise and inform them to contact 111 should it become an emergency. I would love funding to be available to direct people to preventative clinics, so patients are offered the preventative

\section{What would you do?}

Once we dare, ambitions can become infinite. So often we are stifled by others' opinions, doubts or perhaps even our own selfpreservations. All have the ability to put an immediate halt to any expansion of a dream or hopes to progress, the worry being that we are so caught up in our presumed inabilities, brilliant world-changing ideas may not be spoken.

Some will read this and dissect it as fantasy. And perhaps rightly so. We all know that we live in a world that is so directed by

\section{Box 1 The Dental Think Tank}

These ideas come from fellow dental professionals.

If funding wasn't an issue....

'I would set up access clinics ... access clinics for all.' (Dental nurse)

II would start programmes in every nursery, primary and high school with brushing, oral health and diet classes for children so they can brush every morning, break and before they leave.' (Dental therapist)

I would send oral health educators to provide oral health information to pregnant women and new mothers. To help them learn about their oral hygiene and provide diet advice: (Dental hygienist)

'I would work exactly as I was taught at university, always gold standard regardless of expense' (Dentist)

'I would want practices to make better use of Hall crowns; some practices can be put off as it takes two appointments.' (Dental therapist)

'I would convert old buses into mobile dental clinics to drive to homeless shelters and provide treatment.' (Dental therapist)

'I would want more time to be invested in periodontal disease, in management and prevention!' (Dental hygienist)

'I would want to work as a service rather than a business.' (Dental practice manager)

the coin. But that shouldn't stop the voicing of ideas and progress, the ability to think, try, fall, fail, try again and constantly work to be better. Perhaps through these discussions we can recognise ideas that we can start to take steps towards. Dare to dream and who knows what better world we could create?

What would you do if funding wasn't an issue?

https://doi.org/10.1038/s41407-021-0739-0 